\title{
Role of Interleukin-10 in Malaria: Focusing on Coinfection with Lethal and Nonlethal Murine Malaria Parasites
}

\author{
Mamoru Niikura, Shin-Ichi Inoue, and Fumie Kobayashi \\ Department of Infectious Diseases, Kyorin University School of Medicine, Tokyo 181-8611, Japan \\ Correspondence should be addressed to Fumie Kobayashi, fumfum@ks.kyorin-u.ac.jp
}

Received 23 May 2011; Revised 23 August 2011; Accepted 23 August 2011

Academic Editor: Luis I. Terrazas

Copyright ( $) 2011$ Mamoru Niikura et al. This is an open access article distributed under the Creative Commons Attribution License, which permits unrestricted use, distribution, and reproduction in any medium, provided the original work is properly cited.

Interleukin- (IL-) 10, anti-inflammatory cytokine, is known to inhibit the protective immune responses against malaria parasites and to be involved in exacerbating parasitemia during Plasmodium infection. In contrast, IL-10 is regarded as necessary for suppressing severe pathology during Plasmodium infection. Here, we summarize the role of IL-10 during murine malaria infection, focusing especially on coinfection with lethal and nonlethal strains of malaria parasites. Recent studies have demonstrated that the major sources of IL-10 are subpopulations of CD4 ${ }^{+} \mathrm{T}$ cells in humans and mice infected with Plasmodium. We also discuss the influence of innate immunity on the induction of $\mathrm{CD}^{+} \mathrm{T}$ cells during murine malaria coinfection.

\section{Introduction}

Malaria, caused by protozoan parasites of the genus Plasmodium, is the major parasitic disease in tropical and subtropical regions, including parts of the Americas, Asia, and Africa. With more than 200-300 million clinical cases globally and approximately 1 million deaths per year, malaria represents the most important infectious disease worldwide. Four species of Plasmodium infect humans: $P$. falciparum, $P$. vivax, $P$. malariae, and $P$. ovale.

Human malarial parasites develop through two stages in humans: a liver stage and a blood stage. The asexual blood stage of the parasite is the cause of malarial pathologies. Therefore, it is important to prevent the replication of this stage of parasite. Particularly, P. falciparum causes severe pathologies such as cerebral malaria, severe anemia, and respiratory injury in the blood stage. It is necessary to understand the mechanism of protective immunity against the blood stage of the parasite during malaria infection. Nevertheless, it is difficult to investigate the human in vivo immune response against malaria parasite for many reasons. Consequently, murine malaria models with $P$. berghei, $P$. yoelii, and $P$. chabaudi have been used to elucidate the immune interaction in hosts and to demonstrate many factors associated with malarial defense mechanisms [1].

\section{Parasite Killing: The Role of Proinflammatory Cytokines during Human and Murine Malaria Infection}

Interferon- (IFN-) $\gamma$ and Interleukin- (IL-) 12 play a crucial role in the clearance of intracellular pathogens [25]. Low levels of IFN- $\gamma$ and IL-12 production have been observed in young African children with severe anemia during infection with P. falciparum [6]. The IFN- $\gamma$-mediated responses have been shown to be involved in protection against infection with $P$. falciparum [7]. In murine malaria, IFN- $\gamma$ produced by $\mathrm{CD} 4^{+} \mathrm{T}$ cells has been shown to play a pivotal role in protective immunity against $P$. chabaudi $(P c)$ AS [8], nonlethal P. berghei $(P b)$ XAT [9], and P. yoelii $(P y)$ 17XNL [10] infection. Actually, IFN- $\gamma$-depleted mice infected with murine malaria parasites show high levels of parasitemia and eventually die. IL-12 is a necessary factor for clearance of nonlethal $P c$ AS [11], $P b$ XAT [12], and Py 17XNL [13], suggesting that IL-12 plays an important role in protective immunity via IFN $-\gamma$ production in murine malaria. Production of IFN- $\gamma$ and IL-12 is suppressed by anti-inflammatory cytokines such as IL-10. It is possible that enhancement of IL-10 production contributes to suppression of parasite killing, considering that IL-10 plays a detrimental role during $P$. falciparum infection. 


\section{Source and Biological Effect of IL-10}

IL-10, an anti-inflammatory cytokine, plays an important role in regulating immune responses in hosts, as does TGF$\beta$. The major source of IL-10 is known to be T cell subsets including Th1 cells, Th2 cells, $\operatorname{Tr} 1$ cells $\left(\mathrm{CD} 25^{+} \mathrm{Foxp}^{-}{ }^{-}\right)$, and regulatory $\mathrm{T}$ (Treg) cells $\left(\mathrm{CD} 25^{+} \mathrm{Foxp}^{+}\right)$. In antigenprimed $\mathrm{T}$ cells, Th2 cells were originally believed to be the major source of IL-10. Stimulation of Th1 cells with IL-27 upregulates IL-10 production and enhances IFN- $\gamma$ expression slightly $[14,15]$. $\operatorname{Tr} 1$ were identified as a subset of $\mathrm{CD}^{+}$cells that produce high levels of IL-10, low levels of IL-2, but not IL-4. They develop from naïve T cells under the influence of IL-27 [15-17]. IL-10 is also produced by naturally occurring Treg cells [18]. TGF- $\beta$ induces the expression of IL-10 [19]. Moreover, IL-2, an important activator of suppressive activity by Treg cells, enhances IL-10 production $[20,21]$. Today, it is known that the source of IL-10 is not only T cell subsets but also almost all leukocytes [22-25].

Apparently, monocytes/macrophages are the main target cells of inhibitory IL-10 effects [26]: IL-10 inhibits the release of proinflammatory mediators from monocytes/ macrophages, and thereby inhibits the LPS- and IFN- $\gamma$ induced secretion of TNF- $\alpha$, IL- $1 \beta$, IL-6, IL-8, G-CSF, and GM-CSF $[27,28]$. Furthermore, IL-10 inhibits the antigen presentation of monocytes/macrophages. Moreover, the IL-10-induced inhibition of IL-12 synthesis in antigenpresenting cells results in reduced IFN- $\gamma$ production in $\mathrm{T}$ cells [29]. Actually, IL-10 inhibits both the proliferation and the cytokine synthesis of $\mathrm{CD}^{+} \mathrm{T}$ cells, including the production of IL- 2 and IFN- $\gamma$ by Th1 and of IL- 4 and IL- 5 by Th2 [30, 31].

\section{Detrimental Effect of IL-10 on the Outcome of Human and Murine Malaria Infection}

High levels of IL-10 and TNF in plasma have been characteristic of young African children with malarial anemia and high levels of parasitemia [32-39]. In common IL-10 promoter variants, the $-1082 \mathrm{~A} /-819 \mathrm{~T} /-592 \mathrm{~A}$ (ATA) haplotype has been associated with increased susceptibility to severe anemia [39]. Their IL-10: IL-12 ratio was higher than that in the non-ATA haplotype. On the other hand, the -1082G/-819C/592C (GCC) haplotype has been associated with protection against severe anemia [39]. The IL-10:IL-12 ratio in the GCC haplotype was lower than that in the ATA haplotype. These findings suggest that a high IL-10:IL-12 ratio is associated with the downregulation of IFN- $\gamma$ production and that it causes development of severe anemia during $P$. falciparum infection.

Lethal $P y$ 17XL-infected mice show higher levels of IL10 and TGF- $\beta$ production than nonlethal $P y$ 17XNL-infected mice early in infection $[40,41]$. High levels of IL-10 and TGF- $\beta$ are associated with inhibition of proinflammatory response, resulting in high levels of parasitemia, severe anemia by which RBCs ruptured, causing parasite replication and the death of infected mice. Depletion or deficiency of IL$10[40,42]$, or the blockade of IL-10 receptor [41] regulates parasitemia during lethal $P y$ 17XL infection and prolongs survival of infected mice. Couper et al. [42] reported that the major source of IL-10 in lethal $P y$ 17XL-infected mice is $\mathrm{CD} 4^{+} \operatorname{Tr} 1$ cells, just as it is in toxoplasmosis [43] and cutaneous leishmaniasis [44] (Figure 1).

In nonlethal $P y$ 17XNL-infected mice, the production of IL-10 and TGF- $\beta$ is induced in the late phase of infection [41]. The population of $\mathrm{CD}^{+} \operatorname{Tr} 1$ cells has been shown to be the major source of IL-10 in nonlethal Py $17 \mathrm{XNL}$ as well as lethal Py 17XL infection. Moreover, IL-10-deficient mice show marked suppression of the replication of parasites compared with that in wild-type mice [42] (Figure 1). These findings suggest that enhanced-IL-10 production suppresses inflammatory response against malaria parasites, resulting in high levels of parasitemia and anemia by replication of parasites in infected mice. Results show that IL-10 plays a detrimental role during human and murine malaria infection.

\section{Role of Anti-Inflammatory Cytokines during Murine Malaria Infection}

Reportedly, a low IL-10/TNF ratio is associated with severe malarial anemia [36-38]. These results suggest that low levels of IL-10 production are associated with enhancement of TNF production, followed by increased IFN- $y$ production. The enhancement of TNF production might be associated with the aggravation of disease severity, such as severe anemia, by which phagocytosis of uninfected RBC occurs [45], or dyserythropoiesis [46]. Moreover, results obtained using mouse models have suggested that IL-10 plays a protective role in the host during murine malaria infection. Although IL-10-deficient mice show lower levels of parasitemia than wild-type mice do during murine malaria infection, they indicate severe diseases such as hepatic pathology $[42,47,48]$ and cerebral pathology $[49,50]$. Actually, inflammation, which is involved in parasite killing, is upregulated in IL10-deficient mice, but excessive inflammation, such as the increase of IFN- $\gamma$ production, also presents the risk of developing hepatic pathology and/or cerebral pathology. Therefore, it seems that IL-10 might be necessary for suppression of hepatic pathology and cerebral pathology in the host during infection.

B6 mice infected with $P b$ NK65 display hepatic pathology and die within 2 weeks. The development of severe hepatic pathology is involved in IL-12 [11], IFN- $\gamma$, and $\mathrm{CD} 8^{+} \mathrm{T}$ cells [9]. The IL-12 production is induced through a MyD88dependent pathway in DCs or macrophage and engenders hepatic pathology in a perforin/granzyme-dependent manner during $P b$ NK65 infection [51]. Coinfection with nonlethal $\mathrm{Pb}$ XAT or $P y$ 17XNL prevents the development of hepatic pathology caused by $\mathrm{Pb}$ NK65 infection and prolongs survival of mice [47]. In fact, IL-10 KO mice coinfected with nonlethal $\mathrm{Pb}$ XAT or $P y$ 17XNL showed severe hepatic pathology, suggesting that IL-10 is involved in suppression of disease severity during coinfection [47] (Figure 2(b)). During lethal $P y 17 \mathrm{XL}$ or nonlethal $P y 17 \mathrm{XNL}$ infection, IL10 , which is derived from $\mathrm{CD} 4^{+} \operatorname{Tr} 1$ cells, is also necessary for the prevention of hepatic pathology [42]. Nevertheless, it remains unclear whether IFN- $\gamma$ and $\mathrm{CD}^{+} \mathrm{T}$ cells are 


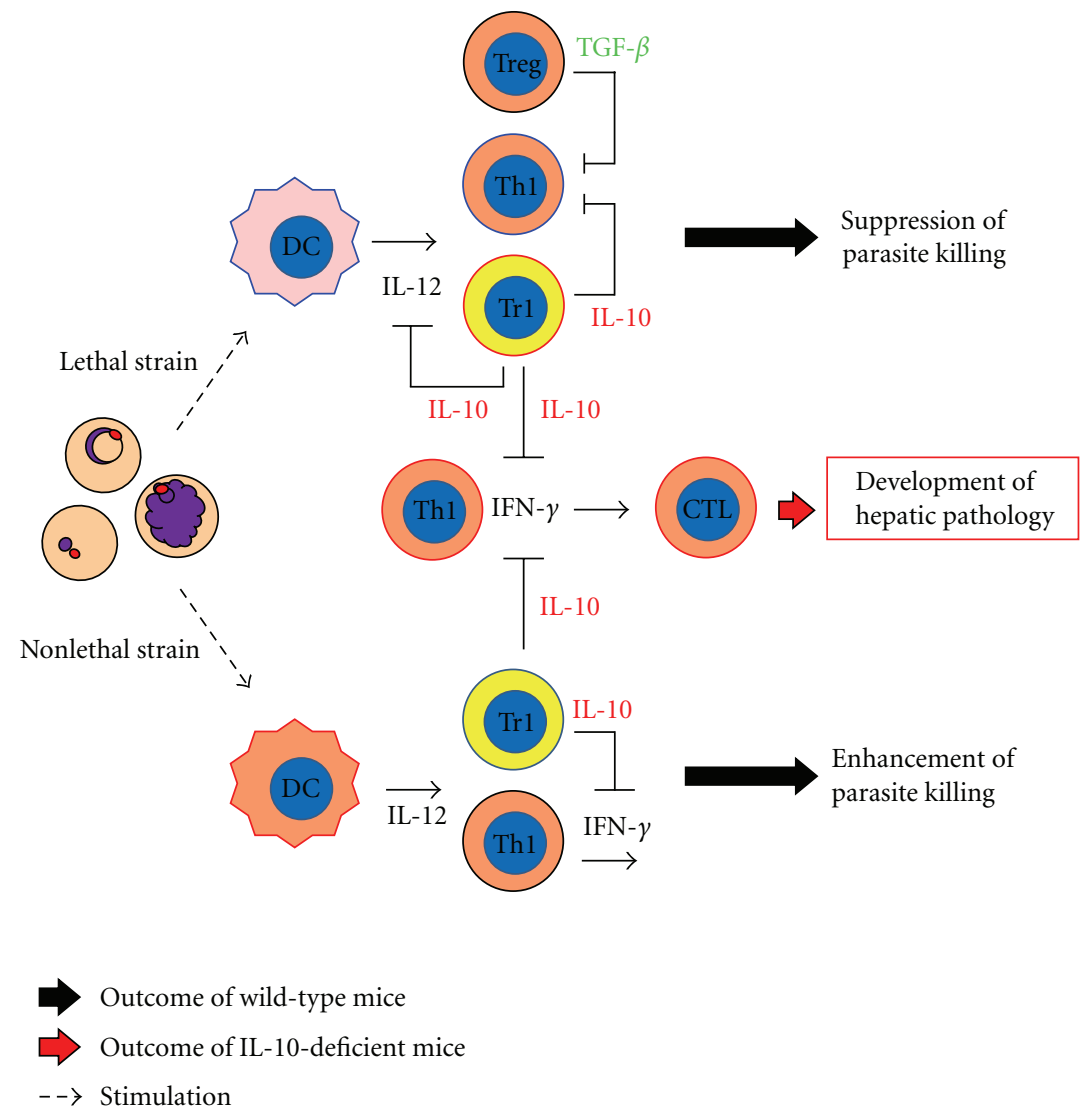

FIGURE 1: Scheme of immune responses during lethal P. yoelii 17XL and nonlethal P. yoelii 17XL infection: DC: dendritic cell; Th: helper T cell (CD4 ${ }^{+}$T cells); Tr1, IL-10-producing CD4 ${ }^{+}$T cells; Treg, regulatory T cells; CTL, cytotoxic T cells (CD8 ${ }^{+} \mathrm{T}$ cells). In a lethal $P$. yoelii $17 \mathrm{XL}$ infection, $\operatorname{Tr} 1$ are induced. IL-10 inhibits proinflammatory cytokine production for parasite killing, producing high levels of parasitemia and the death of mice. Tr1 are also induced in nonlethal $P y$ 17XNL as well as lethal $P y$ 17XL infection. However, parasite killing occurs during nonlethal $P y$ 17XNL infection. When IL-10 is ineffective (depletion or deficiency of IL-10 or the blockade of IL-10 receptor) in mice infected with nonlethal Py 17XNL or lethal Py 17XL, excessive inflammation is induced in association with the development of hepatic pathology.

associated with development of hepatic pathology in mice infected with $P y$ 17XL or Py 17XNL (Figure 1).

Mice infected with $\mathrm{Pb}$ ANKA show similar features to human cerebral malaria (CM) regarding neurologic signs and histopathological findings, considering that $\mathrm{Pb}$ ANKA infection in mice might be an experimental model of CM (ECM) $[52,53]$. Proinflammatory cytokines, such as IFN$\gamma$ and lymphotoxin- $\alpha$, are known to accelerate ECM development [54] (Figure 2(c)). In contrast, anti-inflammatory cytokines, such as IL-10, prevent ECM development $[55,56]$. However, it remains unclear how IL-10 suppresses ECM development, because high levels of IL-10 production were observed in spleen [57] and plasma [58] of mice singly infected with $\mathrm{Pb}$ ANKA.

The ECM development is suppressed by the simultaneous presence of murine AIDS during $\mathrm{Pb}$ ANKA infection [55]. Results demonstrated that murine AIDS-mediated protection of ECM is dependent on IL-10, which is produced by splenic $\mathrm{CD}^{+} \mathrm{T}$ cells, with the use of anti-IL-10 $\mathrm{mAb}$. It is particularly interesting that coinfection with parasites such as nonlethal $\mathrm{Pb}$ XAT [50] or Filaria [59] has also been shown to prevent ECM development. The suppressive effect of coinfection with nonlethal $\mathrm{Pb}$ XAT or Filaria on ECM during $\mathrm{Pb}$ ANKA infection was abrogated in IL-10 KO mice [50, 59], suggesting that IL-10 plays a crucial role in the suppression of ECM during coinfection with other parasites (Figure 2(b)).

In contrast to coinfection with nonlethal $\mathrm{Pb} \mathrm{XAT}$, the suppressive effect of coinfection with nonlethal $P y$ 17XNL on ECM during $\mathrm{Pb}$ ANKA infection is independent of IL$10[50,60]$. A recent study demonstrated that Treg cells, which are expanded by IL-2/anti-IL-2 complexes, suppress the recruitment of pathogenic $\mathrm{CD}^{+}$and $\mathrm{CD}^{+}{ }^{+} \mathrm{T}$ cells to brains and protect mice from developing ECM during $\mathrm{Pb}$ ANKA [61]. The IL-2/anti-IL-2 complexes enhanced the levels of Foxp3 and CTLA-4 expression and increased the levels of IL-10 production from Treg cells during $\mathrm{Pb}$ ANKA infection. However, the suppression of ECM by Treg cells was dependent on CTLA-4 but not on IL-10 [61] (Figure 2(c)). The suppressive effect of coinfection with nonlethal $P y$ 17XNL on ECM during $P b$ ANKA infection was not reversible by depleting antibodies against $\mathrm{CD} 25^{+}$-bearing $\mathrm{CD}^{+}{ }^{+} \mathrm{T}$ cells or $\mathrm{CTLA} 4^{+}$-bearing $\mathrm{CD} 4^{+} \mathrm{T}$ cells [60]. A key factor that has a suppressive effect on ECM by coinfection with nonlethal Py 17XNL has not yet been discovered. 


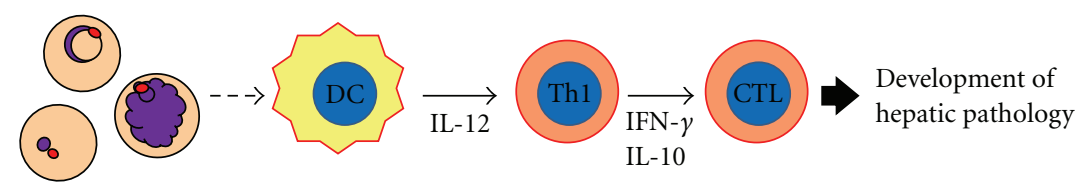

(a)

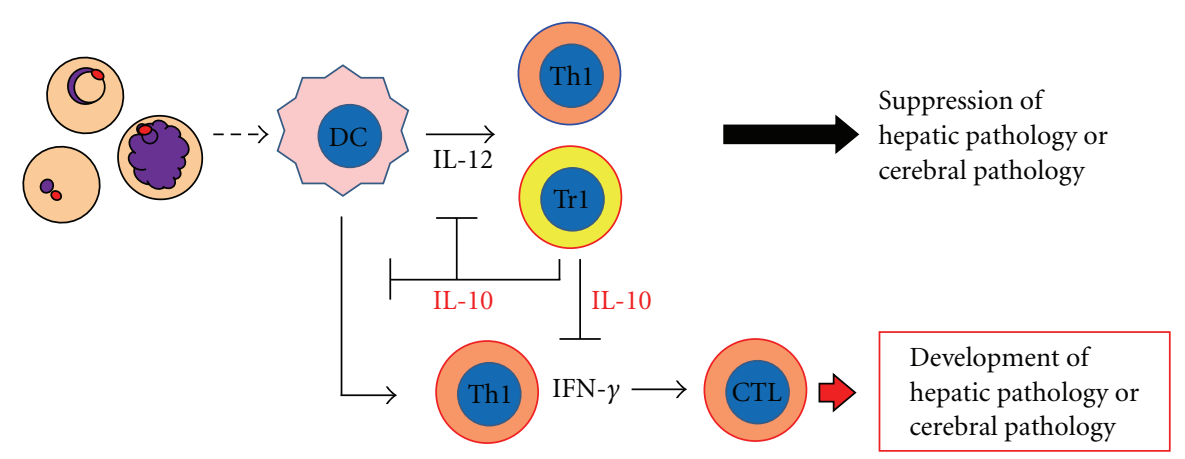

(b)

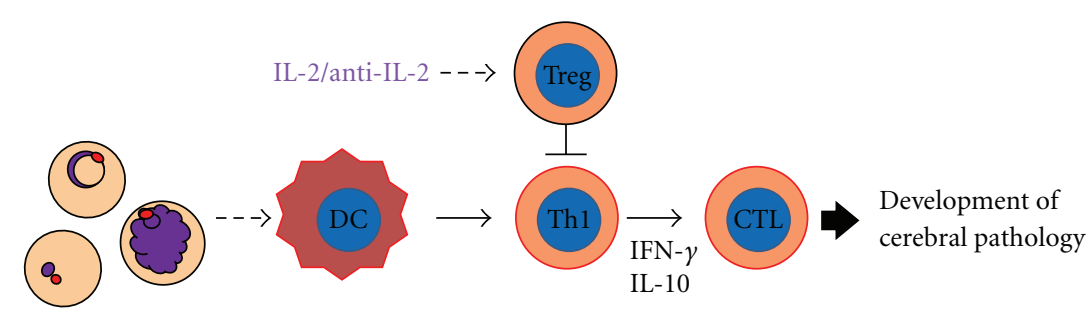

(c)

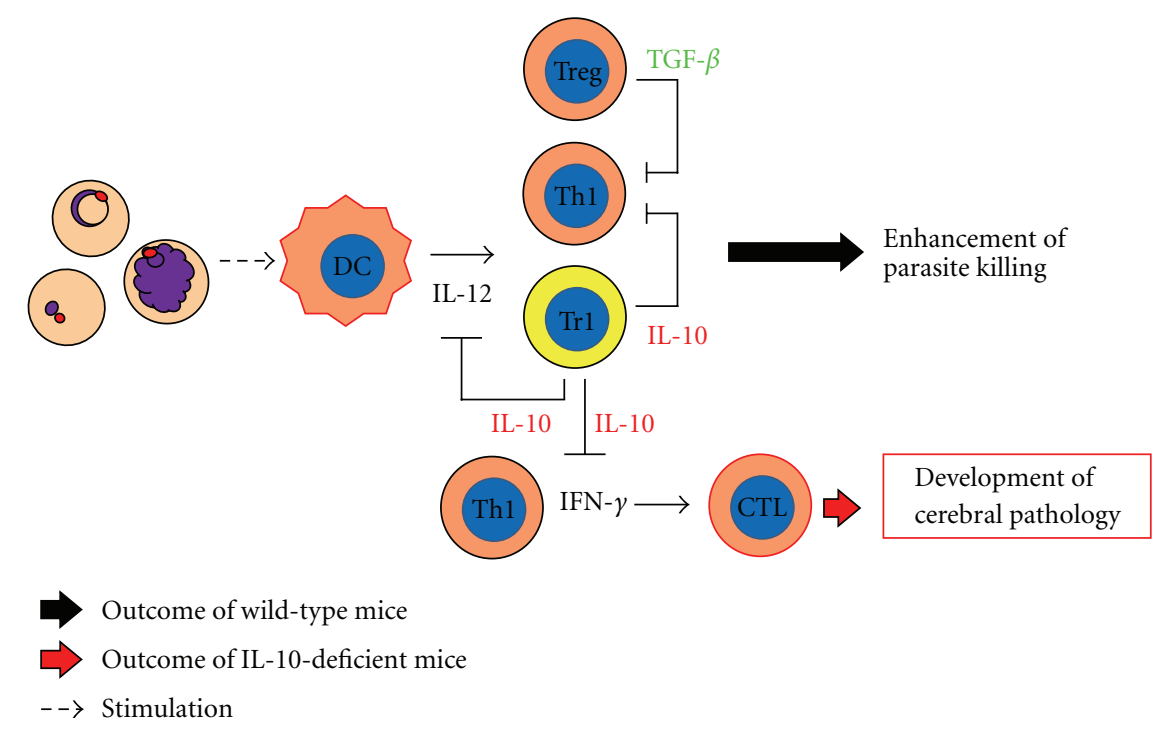

(d)

FIGURE 2: Role of anti-inflammatory responses during murine malaria infection. (a) Immune responses during lethal P. berghei NK65 infection. (b) Possible mechanism by which development of disease severity such as hepatic or cerebral pathology is suppressed by coinfection with nonlethal murine malaria parasites. (c) Immune responses during lethal $P$. berghei ANKA infection. (d) Immune responses during $P$. chabaudi AS infection. (a) and (c) A type of DC activated by lethal P. berghei NK65 or P. berghei ANKA might induce pathological Th1 and CTL. The pathological Th1 and CTL are involved in excessive inflammation and the development of severe pathology, such as hepatic pathology (P. berghei NK65) or experimental cerebral malaria (ECM) (P. berghei ANKA). (b) A type of DC activated by nonlethal malaria parasites before activation by lethal parasites might expand $\operatorname{Tr} 1$, but not pathological Th1, and might subsequently suppress severe disease. IL10, which might be produced by $\operatorname{Tr} 1$, inhibits proinflammatory cytokine production and expansion of pathological Th1 during coinfection. Therefore, coinfected IL-10 deficient mice develop severe pathology, such as hepatic pathology or ECM. (d) In P. chabaudi AS infection, IL-10 from $\operatorname{Tr} 1$ and Treg are associated with suppression of proinflammatory cytokine production and expansion of pathological Th1. A deficiency of IL-10 or TGF- $\beta$ contributes to development of ECM. 
Development of severe disease such as hepatic pathology and cerebral pathology generally involves excessive inflammation in murine malaria parasites. Little is known about the differences between the developmental mechanisms of hepatic pathology and cerebral pathology during $\mathrm{Pb}$ NK65 and $\mathrm{Pb}$ ANKA infection, respectively. However, IL-10 can downregulate excessive inflammation during $P b$ NK65 or $\mathrm{Pb}$ ANKA infection. It is associated with the suppression of hepatic pathology and cerebral pathology. Results show that IL-10 plays a protective role in the host during $P$. falciparum infection.

\section{A Different Type of DC Induced by Lethal and Nonlethal Murine Malaria Infection}

How are different subsets of $\mathrm{CD} 4^{+} \mathrm{T}$ cells, such as pathological $\mathrm{CD}^{+}{ }^{+} \mathrm{T}$ cells $[62,63]$, IL-10-producing $\mathrm{CD}^{+} \mathrm{T}$ cells [42], and Treg cells [64], induced between lethal and nonlethal murine malaria infection? The development of $\mathrm{CM}$ is inhibited completely by the simultaneous presence of nonlethal $P y$ 17XNL [60], lethal $P b$ K173 [57], and nonlethal $\mathrm{Pb}$ XAT [50]. However, protection from $\mathrm{CM}$ was not induced in mice when they were infected with $P y$ 17XNL on day 4 after $\mathrm{Pb}$ ANKA infection [60]. Similarly, coinfection with $\mathrm{Pb}$ XAT on day 1 or day 3 after infection with $P b$ ANKA failed to protect mice from cerebral malaria (Niikura et al. unpublished data). In simultaneous infection with $\mathrm{Pb}$ ANKA and $P b$ K173, suppression of ECM was associated with the induction of cytokines such as IFN- $\gamma$, IL-10, and IL-12 on day 1 after infection [57]. These findings suggest that the presence of other parasites might modulate some key factors/cells that are involved in innate immunity in early infection with $\mathrm{Pb}$ ANKA. Actually, DCs are important for initiating immune responses against malaria parasites. It is possible that immune responses induced by DCs produce protective and pathological effects, respectively, when mice are infected with nonlethal and lethal parasites. Therefore, DCs might contribute to the determination of the virulence of malaria parasites. In coinfection, a type of DC activated by nonlethal malaria parasites before activation by lethal parasites might fail to expand pathological $\mathrm{CD} 4^{+} \mathrm{T}$ cells and subsequently fail to suppress severe disease.

Wykes et al. [13] showed that although DCs from mice infected with nonlethal Py 17XNL were fully functional, DCs from mice infected with lethal $P y$ YM were unable to produce IL-12 or present antigens to T cells. Apparently, lethal malaria causes a failure of DC function, resulting in the suppression of Th1 immune responses (Figure 1). Similar to lethal $P y$ 17XL infected mice, it is possible that mice infected with lethal Py YM induce IL-10-producing $\mathrm{CD}^{+}{ }^{+} \mathrm{T}$ cells. Although IL-10 might inhibit the DC function, such as antigen presentation and release of proinflammatory cytokines, little is known about whether IL-10 associates with a different type of DC induced between lethal and nonlethal murine malaria infection. Toll-like receptors (TLRs) play an important role in the innate immune system against pathogens [65]. Therefore, TLRs might be associated with disease severity during malaria infection. During lethal $P y$
17XL infection, TLR9 signaling in DCs is known to be crucial for the activation of Treg cells that suppress Th1 immune responses, causing high levels of parasitemia [64]. In contrast, MyD88, but not TLR signaling, has been shown to be necessary for elimination of parasites in mice infected with nonlethal Py 17XNL [66]. Accordingly, a different type of DC induced between lethal and nonlethal murine malaria infection might induce different subsets of $\mathrm{CD} 4^{+} \mathrm{T}$ cells, such as IL-10-producing $\mathrm{CD} 4^{+} \mathrm{T}$ cells or Treg cells.

\section{Is IL-10 Necessary for Host Protection against Murine Malaria Parasites?}

Although IL-10-deficient mice suppressed an increase of parasitemia during coinfection with lethal and nonlethal parasites, mice were unable to eliminate parasites completely and eventually died $[47,50]$. These results suggest that the lethal strains of malaria parasites may modulate the induction of adaptive immunity independent of IL-10. Millington et al. [67] demonstrated that Plasmodium infection inhibits the induction of adaptive immunity to heterologous antigens by modulating DC function. According to their paper, hemozoin (HZ), rather than infected RBC membranes, was a key factor involved in the suppression of murine DC function. On the other hand, it has been shown that repeated stimulation through TLR9, which is the receptor for HZ, engenders tolerance to signaling through TLR4 [68].

In fact, $\mathrm{HZ}$ activates DCs through the TLR9-MyD88 pathway [69]. A recent study has demonstrated that parasite protein-DNA complex, but not $\mathrm{HZ}$, plays a crucial role in TLR9-mediated activation of DCs during infection [70]. Stimulation through TLR9 might be associated with development of severe hepatic pathology, because MyD88 pathway, which is activated by TLR9 stimulation, is known to be involved in severe hepatic pathology caused by $P b$ NK65 [51]. Coban et al. [71] and Griffith et al. [72] reported that the TLRs-MyD88 signaling pathway might play a critical role in ECM during lethal $\mathrm{Pb}$ ANKA infection. It has been shown that ECM is prevented by oral treatment with E6446, which is a synthetic antagonist of nucleic acid-sensing TLRs [73]. In contrast, it is demonstrated that murine cerebral malaria development is independent of Toll-like receptor signaling $[74,75]$. It remains controversial whether TLRs-MyD88 signaling pathway is associated with ECM development.

In summary, IL-10 is necessary for suppression of hepatic pathology or ECM in the host although IL-10 entails a risk of downregulation of protective immunity against malaria parasites. $\mathrm{CD} 4^{+} \mathrm{T}$ cells of different kinds, such as pathological CD4 ${ }^{+} \mathrm{T}$ cells, IL-10-producing $\mathrm{CD} 4^{+} \mathrm{T}$ cells, or Treg cells, are induced during different kinds of Plasmodium spp infection. To induce a more effective immune response in host defense against Plasmodium spp, it is necessary to elucidate the interaction of innate and acquired immune cells such as DCs, $\alpha \beta$ T cells, and $\gamma \delta$ T cells.

\section{Acknowledgments}

This work was supported by Grant-in-Aid no. 20590428 for Scientific Research (C) to F. Kobayashi and Grant-in-Aid 
no. 21790410 for young Scientists (B) to M. Niikura from the Japan Society for the Promotion of Science.

\section{References}

[1] M. Hernandez-Valladares, J. Naessens, and F. A. Iraqi, "Genetic resistance to malaria in mouse models," Trends in Parasitology, vol. 21, no. 8, pp. 352-355, 2005.

[2] M. M. Stevenson, M. F. Tam, M. Belosevic, P. H. Van Der Meide, and J. E. Podoba, "Role of endogenous gamma interferon in host response to infection with blood-stage Plasmodium chabaudi AS," Infection and Immunity, vol. 58, no. 10, pp. 3225-3232, 1990.

[3] J. P. Sypek, C. L. Chung, S. E. H. Mayor et al., "Resolution of cutaneous leishmaniasis: interleukin 12 initiates a protective $\mathrm{T}$ helper type 1 immune response," Journal of Experimental Medicine, vol. 177, no. 6, pp. 1797-1802, 1993.

[4] R. T. Gazzinelli, S. Hieny, T. A. Wynn, S. Wolf, and A. Sher, "Interleukin 12 is required for the T-lymphocyte-independent induction of interferon $\gamma$ by an intracellular parasite and induces resistance in T-cell- deficient hosts," Proceedings of the National Academy of Sciences of the United States of America, vol. 90, no. 13, pp. 6115-6119, 1993.

[5] R. T. Gazzinelli, M. Wysocka, S. Hayashi et al., "Parasiteinduced IL-12 stimulates early IFN- $\gamma$ synthesis and resistance during acute infection with Toxoplasma gondii," Journal of Immunology, vol. 153, no. 6, pp. 2533-2543, 1994.

[6] A. J. F. Luty, D. J. Perkins, B. Lell et al., "Low interleukin-12 activity in severe Plasmodium falciparum malaria," Infection and Immunity, vol. 68, no. 7, pp. 3909-3915, 2000.

[7] A. J. F. Luty, B. Lell, R. Schmidt-Ott et al., "Interferon- $\gamma$ responses are associated with resistance to reinfection with Plasmodium falciparum in young African children," Journal of Infectious Diseases, vol. 179, no. 4, pp. 980-988, 1999.

[8] I. A. Clark, N. H. Hunt, G. A. Butcher, and W. B. Cowden, "Inhibition of murine malaria (Plasmodium chabaudi) in vivo by recombinant interferon- $\gamma$ or tumor necrosis factor, and its enhancement by butylated hydroxyanisole," Journal of Immunology, vol. 139, no. 10, pp. 3493-3496, 1987.

[9] S. Waqki, S. Uehara, K. Kanbe, K. Ono, M. Suzuki, and H. Nariuchi, "The role of $\mathrm{T}$ cells in pathogenesis and protective immunity to murine malaria," Immunology, vol. 75, no. 4, pp. 646-651, 1992.

[10] F. Kobayashi, T. Morii, T. Matsui et al., "Production of interleukin 10 during malaria caused by lethal and nonlethal variants of Plasmodium yoelii yoelii," Parasitology Research, vol. 82, no. 5, pp. 385-391, 1996.

[11] Z. Su and M. M. Stevenson, "IL-12 is required for antibodymediated protective immunity against blood-stage Plasmodium chabaudi AS malaria infection in mice," Journal of Immunology, vol. 168, no. 3, pp. 1348-1355, 2002.

[12] T. Yoshimoto, T. Yoneto, S. Waki, and H. Nariuchi, "Interleukin-12-dependent mechanisms in the clearance of blood-stage murine malaria parasite Plasmodium berghei XAT, an attenuated variant of $P$. berghei NK65," Journal of Infectious Diseases, vol. 177, no. 6, pp. 1674-1681, 1998.

[13] M. N. Wykes, X. Q. Liu, L. Beattie et al., "Plasmodium strain determines dendritic cell function essential for survival from malaria," PLoS Pathogens, vol. 3, no. 7, Article ID e96, 2007.

[14] C. F. Anderson, J. S. Stumhofer, C. A. Hunter, and D. Sacks, "IL-27 regulates IL-10 and IL-17 from CD4 ${ }^{+}$cells in nonhealing Leishmania major infection," Journal of Immunology, vol. 183, no. 7, pp. 4619-4627, 2009.
[15] J. S. Stumhofer, J. S. Silver, A. Laurence et al., "Interleukins 27 and 6 induce STAT3-mediated T cell production of interleukin 10," Nature Immunology, vol. 8, no. 12, pp. 1363-1371, 2007.

[16] M. Batten, N. M. Kljavin, J. Li, M. J. Walter, F. J. De Sauvage, and N. Ghilardi, "Cutting edge: IL-27 is a potent inducer of IL10 but not FoxP3 in murine T cells," Journal of Immunology, vol. 180, no. 5, pp. 2752-2756, 2008.

[17] G. Murugaiyan, A. Mittal, R. Lopez-Diego, L. M. Maier, D. E. Anderson, and H. L. Weiner, "IL-27 is a key regulator of IL10 and IL-17 production by human $\mathrm{CD}^{+} \mathrm{T}$ cells," Journal of Immunology, vol. 183, no. 4, pp. 2435-2443, 2009.

[18] C. L. Maynard, L. E. Harrington, K. M. Janowski et al., "Regulatory T cells expressing interleukin 10 develop from Foxp $3^{+}$ and Foxp $3^{-}$precursor cells in the absence of interleukin 10," Nature Immunology, vol. 8, no. 9, pp. 931-941, 2007.

[19] C. L. Maynard, R. D. Hatton, W. S. Helms, J. R. Oliver, C. B. Stephensen, and C. T. Weaver, "Contrasting roles for all-trans retinoic acid in TGF- $\beta$-mediated induction of Foxp 3 and Il10 genes in developing regulatory T cells," Journal of Experimental Medicine, vol. 206, no. 2, pp. 343-357, 2009.

[20] S. Brandenburg, T. Takahashi, M. de la Rosa et al., "IL-2 induces in vivo suppression by $\mathrm{CD} 4{ }^{+} \mathrm{CD} 25^{+} \mathrm{Foxp} 3^{+}$regulatory T cells," European Journal of Immunology, vol. 38, no. 6, pp. 1643-1653, 2008.

[21] K. Tsuji-Takayama, M. Suzuki, M. Yamamoto et al., "The production of IL-10 by human regulatory $\mathrm{T}$ cells is enhanced by IL-2 through a STAT5-responsive intronic enhancer in the IL-10 locus," Journal of Immunology, vol. 181, no. 6, pp. 38973905, 2008.

[22] M. Murai, O. Turovskaya, G. Kim et al., "Interleukin 10 acts on regulatory $\mathrm{T}$ cells to maintain expression of the transcription factor Foxp3 and suppressive function in mice with colitis," Nature immunology, vol. 10, no. 11, pp. 1178-1184, 2009.

[23] A. Roers, L. Siewe, E. Strittmatter et al., "T cell-specific inactivation of the interleukin 10 gene in mice results in enhanced $\mathrm{T}$ cell responses but normal innate responses to lipopolysaccharide or skin irritation," Journal of Experimental Medicine, vol. 200, no. 10, pp. 1289-1297, 2004.

[24] S. Seki, S. I. Osada, S. Ono et al., "Role of liver NK cells and peritoneal macrophages in gamma interferon and interleukin, 10 production in experimental bacterial peritonitis in mice," Infection and Immunity, vol. 66, no. 11, pp. 5286-5294, 1998.

[25] L. Siewe, M. Bollati-Fogolin, C. Wickenhauser, T. Krieg, W. Müller, and A. Roers, "Interleukin-10 derived from macrophages and/or neutrophils regulates the inflammatory response to LPS but not the response to CpG DNA," European Journal of Immunology, vol. 36, no. 12, pp. 3248-3255, 2006.

[26] R. Sabat, G. Grütz, K. Warszawska et al., "Biology of interleukin-10," Cytokine and Growth Factor Reviews, vol. 21, no. 5, pp. 331-344, 2010.

[27] R. De Waal Malefyt, J. Abrams, B. Bennett, C. G. Figdor, and J. E. De Vries, "Interleukin 10(IL-10) inhibits cytokine synthesis by human monocytes: an autoregulatory role of IL10 produced by monocytes," Journal of Experimental Medicine, vol. 174, no. 5, pp. 1209-1220, 1991.

[28] D. F. Fiorentino, A. Zlotnik, T. R. Mosmann, M. Howard, and A. O'Garra, "IL-10 inhibits cytokine production by activated macrophages," Journal of Immunology, vol. 147, no. 11, pp. 3815-3822, 1991. 
[29] A. D’Andrea, M. Aste-Amezaga, N. M. Valiante, X. Ma, M. Kubin, and G. Trinchieri, "Interleukin 10 (IL-10) inhibits human lymphocyte interferon $\gamma$-production by suppressing natural killer cell stimulatory factor/IL-12 synthesis in accessory cells," Journal of Experimental Medicine, vol. 178, no. 3, pp. 1041-1048, 1993.

[30] G. Del Prete, M. De Carli, F. Almerigogna, M. G. Giudizi, R. Biagiotti, and S. Romagnani, "Human IL-10 is produced by both type 1 helper (Th1) and type 2 helper (Th2) T cell clones and inhibits their antigen-specific proliferation and cytokine production," Journal of Immunology, vol. 150, no. 2, pp. 353360, 1993.

[31] H. Groux, M. Bigler, J. E. De Vries, and M. G. Roncarolo, "Interleukin-10 induces a long-term antigen-specific anergic state in human $\mathrm{CD}^{+} \mathrm{T}$ cells," Journal of Experimental Medicine, vol. 184, no. 1, pp. 19-29, 1996.

[32] V. P. Gopinathan and A. R. Subramanian, "Vivax and falciparum malaria seen at an Indian service hospital," Journal of Tropical Medicine and Hygiene, vol. 89, no. 2, pp. 51-55, 1986.

[33] G. E. Grau, T. E. Taylor, M. E. Molyneux et al., "Tumor necrosis factor and disease severity in children with falciparum malaria," The New England Journal of Medicine, vol. 320, no. 24, pp. 1586-1591, 1989.

[34] D. Kwiatkowski, A. V. S. Hill, I. Sambou et al., "TNF concentration in fatal cerebral, non-fatal cerebral, and uncomplicated Plasmodium falciparum malaria," The Lancet, vol. 336, no. 8725, pp. 1201-1204, 1990.

[35] N. Shaffer, G. E. Grau, K. Hedberg et al., "Tumor necrosis factor and severe malaria," Journal of Infectious Diseases, vol. 163, no. 1, pp. 96-101, 1991.

[36] B. G. Mordmüller, W. G. Metzger, P. Juillard et al., "Tumor necrosis factor in Plasmodium falciparum malaria: high plasma level is associated with fever, but high production capacity is associated with rapid fever clearance," European Cytokine Network, vol. 8, no. 1, pp. 29-35, 1997.

[37] J. A. L. Kurtzhals, V. Adabayeri, B. Q. Goka et al., "Low plasma concentrations of interleukin-10 in severe malarial anaemia compared with cerebral and uncomplicated malaria," The Lancet, vol. 351, no. 9118, pp. 1768-1772, 1998.

[38] C. Othoro, A. A. Lal, B. Nahlen, D. Koech, A. S. S. Orago, and V. Udhayakumar, "A low interleukin-10 tumor necrosis factor$\alpha$ ratio is associated with malaria anemia in children residing in a holoendemic malaria region in western Kenya," Journal of Infectious Diseases, vol. 179, no. 1, pp. 279-282, 1999.

[39] C. Ouma, G. C. Davenport, T. Were et al., "Haplotypes of IL-10 promoter variants are associated with susceptibility to severe malarial anemia and functional changes in IL-10 production," Human Genetics, vol. 124, no. 5, pp. 515-524, 2008.

[40] F. Kobayashi, H. Ishida, T. Matsui, and M. Tsuji, "Effects of in vivo administration of anti-IL-10 or anti-IFN- $\gamma$ monoclonal antibody on the host defense mechanism against Plasmodium yoelii yoelii infection," Journal of Veterinary Medical Science, vol. 62 , no. 6 , pp. $583-587,2000$

[41] F. M. Omer, J. B. De Souza, and E. M. Riley, "Differential induction of TGF- $\beta$ regulates proinflammatory cytokine production and determines the outcome of lethal and nonlethal Plasmodium yoelii infections," Journal of Immunology, vol. 171, no. 10, pp. 5430-5436, 2003.

[42] K. N. Couper, D. G. Blount, M. S. Wilson et al., "IL-10 from $\mathrm{CD} 4{ }^{+} \mathrm{CD} 25^{-} \mathrm{Foxp}^{-} \mathrm{CD} 127^{-}$adaptive regulatory $\mathrm{T}$ cells modulates parasite clearance and pathology during malaria infection," PLoS Pathogens, vol. 4, no. 2, Article ID e1000004, 2008.
[43] D. Jankovic, M. C. Kullberg, C. G. Feng et al., "Conventional Tbet ${ }^{+}$Foxp $3^{-}$Th1 cells are the major source of host-protective regulatory IL-10 during intracellular protozoan infection," Journal of Experimental Medicine, vol. 204, no. 2, pp. 273-283, 2007.

[44] C. F. Anderson, M. Oukka, V. J. Kuchroo, and D. Sacks, "CD4 ${ }^{+} \mathrm{CD} 25-$ Foxp3 $3^{-}$Th1 cells are the source of IL-10mediated immune suppression in chronic cutaneous leishmaniasis," Journal of Experimental Medicine, vol. 204, no. 2, pp. 285-297, 2007.

[45] H. U. Lutz, M. Pfister, and R. Hornig, "Tissue homeostatic role of naturally occurring anti-band 3 antibodies," Cellular and Molecular Biology, vol. 42, no. 7, pp. 995-1005, 1996.

[46] I. A. Clark and G. Chaudhri, "Tumour necrosis factor may contribute to the anaemia of malaria by causing dyserythropoiesis and erythrophagocytosis," British Journal of Haematology, vol. 70, no. 1, pp. 99-103, 1988.

[47] M. Niikura, S. Kamiya, K. Kita, and F. Kobayashi, "Coinfection with nonlethal murine malaria parasites suppresses pathogenesis caused by Plasmodium berghei NK65," Journal of Immunology, vol. 180, no. 10, pp. 6877-6884, 2008.

[48] E. G. Findlay, R. Greig, J. S. Stumhofer et al., "Essential role for IL-27 receptor signaling in prevention of Th1mediated immunopathology during malaria infection," Journal of Immunology, vol. 185, no. 4, pp. 2482-2492, 2010.

[49] L. A. Sanni, W. Jarra, C. Li, and J. Langhorne, "Cerebral edema and cerebral hemorrhages in interleukin-10-deficient mice infected with Plasmodium chabaudi, Infection and Immunity, vol. 72, no. 5, pp. 3054-3058, 2004.

[50] M. Niikura, S. Kamiya, A. Nakane, K. Kita, and F. Kobayashi, "IL-10 plays a crucial role for the protection of experimental cerebral malaria by co-infection with non-lethal malaria parasites," International Journal for Parasitology, vol. 40, no. 1, pp. 101-108, 2010.

[51] K. Adachi, H. Tsutsui, S. I. Kashiwamura et al., "Plasmodium berghei infection in mice induces liver injury by an IL-12- and toll-like receptor/myeloid differentiation factor 88-dependent mechanism," Journal of Immunology, vol. 167, no. 10, pp. 5928-5934, 2001.

[52] M. Yoeli, "Cerebral malaria: the quest for suitable experimental models in parasitic diseases of man," Transactions of the Royal Society of Tropical Medicine and Hygiene, vol. 70, no. 1, pp. 24-35, 1976.

[53] J. Lou, R. Lucas, and G. E. Grau, "Pathogenesis of cerebral malaria: recent experimental data and possible applications for humans," Clinical Microbiology Reviews, vol. 14, no. 4, pp. 810-820, 2001.

[54] N. H. Hunt and G. E. Grau, "Cytokines: accelerators and brakes in the pathogenesis of cerebral malaria," Trends in Immunology, vol. 24, no. 9, pp. 491-499, 2003.

[55] M. Eckwalanga, M. Marussig, M. D. Tavares et al., "Murine AIDS protects mice against experimental cerebral malaria: down- regulation by interleukin 10 of a T-helper type $1 \mathrm{CD}^{+}$ cell-mediated pathology," Proceedings of the National Academy of Sciences of the United States of America, vol. 91, no. 17, pp. 8097-8101, 1994.

[56] S. Kossodo, C. Monso, P. Juillard, T. Velu, M. Goldman, and G. E. Grau, "Interleukin-10 modulates susceptibility in experimental cerebral malaria," Immunology, vol. 91, no. 4, pp. 536-540, 1997.

[57] A. J. Mitchell, A. M. Hansen, L. Hee et al., "Early cytokine production is associated with protection from murine cerebral malaria," Infection and Immunity, vol. 73, no. 9, pp. 5645$5653,2005$. 
[58] L. M. Randall, F. H. Amante, K. A. McSweeney et al., "Common strategies to prevent and modulate experimental cerebral malaria in mouse strains with different susceptibilities," Infection and Immunity, vol. 76, no. 7, pp. 3312-3320, 2008.

[59] S. Specht, D. F. Ruiz, B. Dubben, S. Deininger, and A. Hoerauf, "Filaria-induced IL-10 suppresses murine cerebral malaria," Microbes and Infection, vol. 12, no. 8-9, pp. 635-642, 2010.

[60] T. Voza, A. M. Vigário, E. Belnoue et al., "Species-specific inhibition of cerebral malaria in mice coinfected with Plasmodium spp," Infection and Immunity, vol. 73, no. 8, pp. 4777-4786, 2005.

[61] A. Haque, S. E. Best, F. H. Amante et al., "Cd4 $4^{+}$natural regulatory t cells prevent experimental cerebral malaria via CTLA-4 when expanded in vivo," PLoS Pathogens, vol. 6, no. 12, Article ID e1001221, 2010.

[62] D. S. Hansen, N. J. Bernard, C. Q. Nie, and L. Scholeld, "NK cells stimulate recruitment of $\mathrm{CXCR}^{+} \mathrm{T}$ cells to the brain during Plasmodium berghei-mediated cerebral malaria," Journal of Immunology, vol. 178, no. 9, pp. 5779-5788, 2007.

[63] G. S. V. Campanella, A. M. Tager, J. K. El Khoury et al., "Chemokine receptor CXCR3 and its ligands CXCL9 and CXCL10 are required for the development of murine cerebral malaria," Proceedings of the National Academy of Sciences of the United States of America, vol. 105, no. 12, pp. 4814-4819, 2008.

[64] H. Hisaeda, K. Tetsutani, T. Imai et al., "Malaria parasites require TLR9 signaling for immune evasion by activating regulatory T cells," Journal of Immunology, vol. 180, no. 4, pp. 2496-2503, 2008.

[65] T. Kawai and S. Akira, "The role of pattern-recognition receptors in innate immunity: update on toll-like receptors," Nature Immunology, vol. 11, no. 5, pp. 373-384, 2010.

[66] J. P. Cramer, B. Lepenies, F. Kamena et al., "MyD88/IL-18-dependent pathways rather than TLRs control early parasitaemia in non-lethal Plasmodium yoelii infection," Microbes and Infection, vol. 10, no. 12-13, pp. 1259-1265, 2008.

[67] O. R. Millington, C. Di Lorenzo, R. S. Phillips, P. Garside, and J. M. Brewer, "Suppression of adaptive immunity to heterologous antigens during Plasmodium infection through hemozoin-induced failure of dendritic cell function," Journal of Biology, vol. 5, article no. 5, 2006.

[68] S. J. Yeo, J. G. Yoon, S. C. Hong, and A. K. Yi, "CpG DNA induces self and cross-hyporesponsiveness of RAW264.7 cells in response to CpG DNA and lipopolysaccharide: alterations in IL-1 receptor-associated kinase expression," Journal of Immunology, vol. 170, no. 2, pp. 1052-1061, 2003.

[69] C. Coban, K. J. Ishii, T. Kawai et al., "Toll-like receptor 9 mediates innate immune activation by the malaria pigment hemozoin," Journal of Experimental Medicine, vol. 201, no. 1, pp. 19-25, 2005.

[70] X. Wu, N. M. Gowda, S. Kumar, and D. C. Gowda, "ProteinDNA complex is the exclusive malaria parasite component that activates dendritic cells and triggers innate immune responses," Journal of Immunology, vol. 184, no. 8, pp. 43384348, 2010.

[71] C. Coban, S. Uematsu, N. Arisue et al., "Pathological role of Toll-like receptor signaling in cerebral malaria," International Immunology, vol. 19, no. 1, pp. 67-79, 2007.

[72] J. W. Griffith, C. O’Connor, K. Bernard, T. Town, D. R. Goldstein, and R. Bucala, "Toll-like receptor modulation of murine cerebral malaria is dependent on the genetic background of the host," Journal of Infectious Diseases, vol. 196, no. 10, pp. 1553-1564, 2007.
[73] B. S. Franklin, S. T. Ishizaka, M. Lamphier et al., "Therapeutical targeting of nucleic acid-sensing Toll-like receptors prevents experimental cerebral malaria," Proceedings of the $\mathrm{Na}$ tional Academy of Sciences of the United States of America, vol. 108, no. 9, pp. 3689-3694, 2011.

[74] D. Togbe, L. Schofield, G. E. Grau et al., "Murine cerebral malaria development is independent of toll-like receptor signaling," American Journal of Pathology, vol. 170, no. 5, pp. 1640-1648, 2007.

[75] B. Lepenies, J. P. Cramer, G. D. Burchard, H. Wagner, C. J. Kirschning, and T. Jacobs, "Induction of experimental cerebral malaria is independent of TLR2/4/9," Medical Microbiology and Immunology, vol. 197, no. 1, pp. 39-44, 2008. 

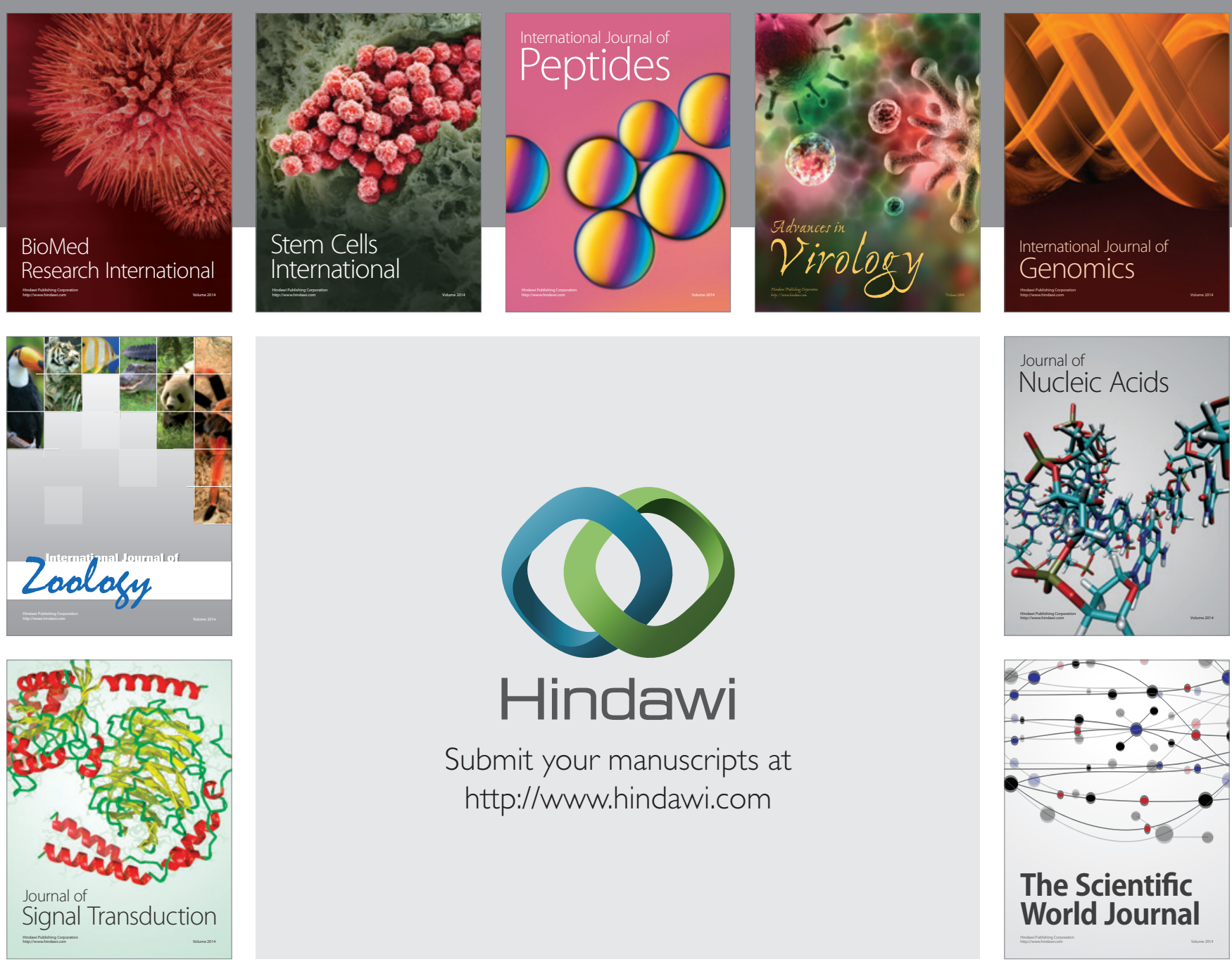

Submit your manuscripts at

http://www.hindawi.com
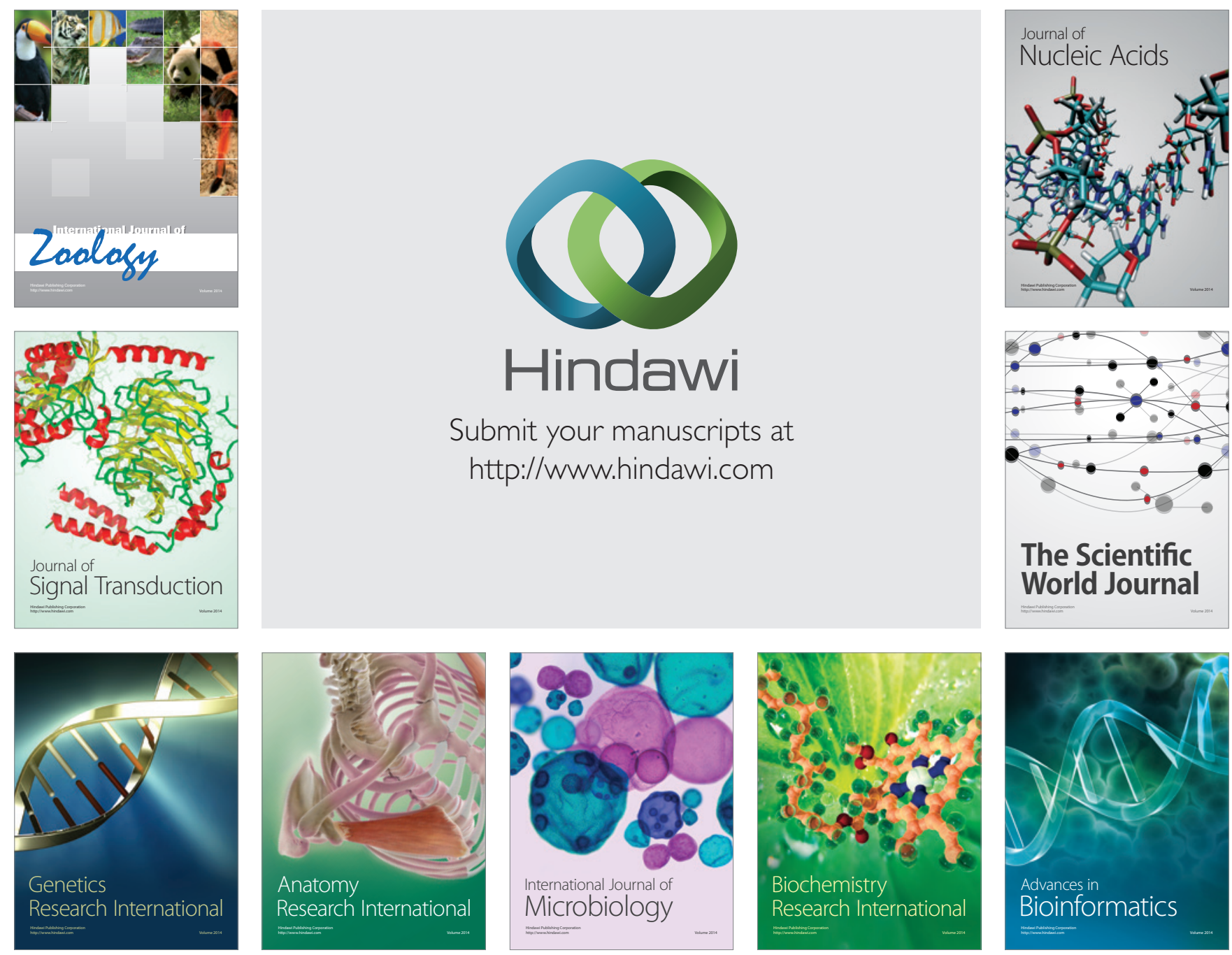

The Scientific World Journal
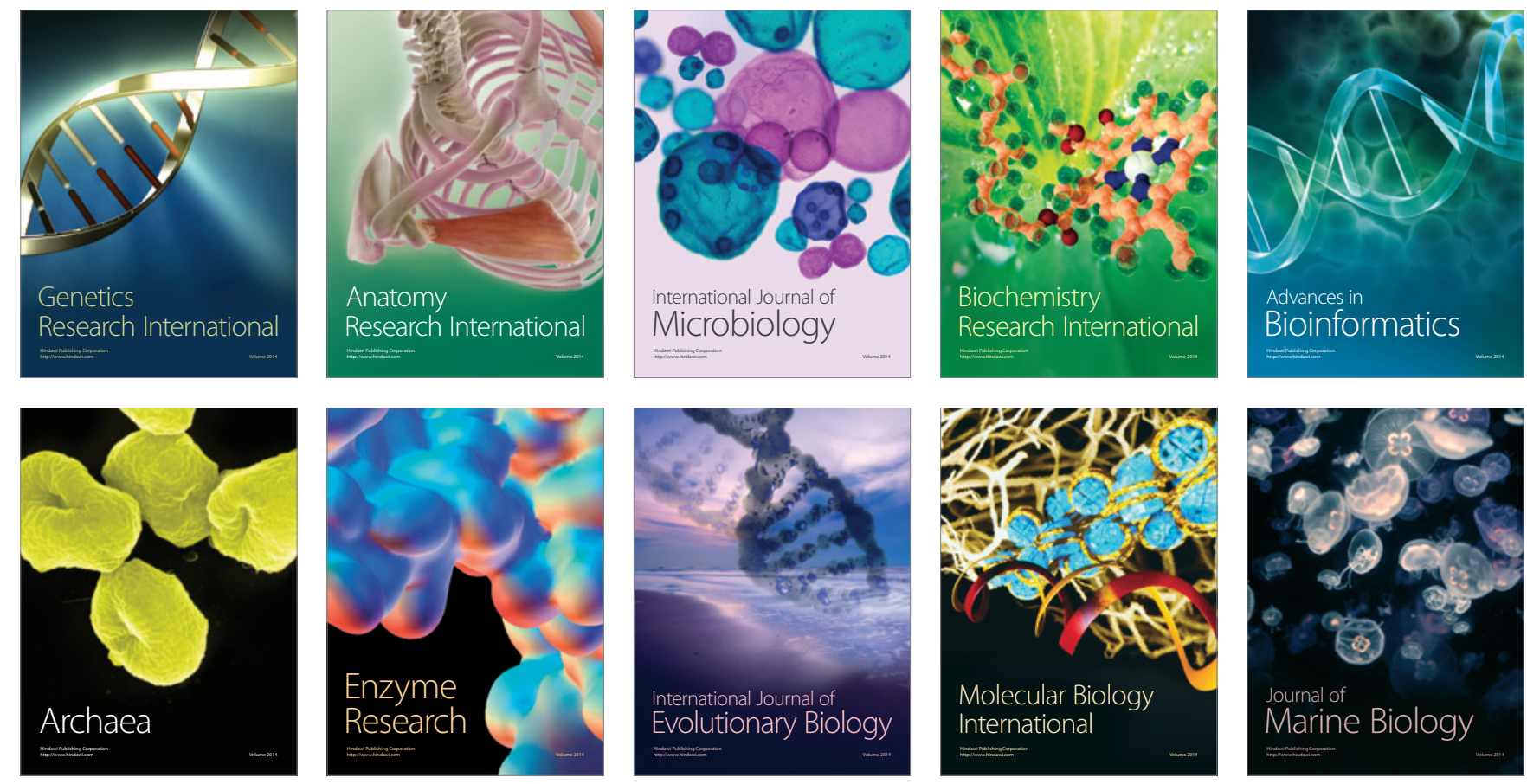